"In the above table the fall or rise in the barometric pressure is corrected for the daily variation, and from 9 a.m. on the 24 th to 9 a.m. on the 29 th the mean hourly velocities of the wind are given, whereas from Io a.m. to 5 p.m. on the 29 th the rates of the velocity per hour are given as obtained from observations taken during intervals of two to five minutes.

"It will be seen that at 2 p.m. on the 29 th the barometer was at $27^{\circ} 990$ inches; that from noon to 2 p.m. it fell $\mathrm{I}^{\circ} \mathrm{O} 45$ inch; that from 3 to 5 p.m. it rose $\mathrm{I}^{\circ} \mathrm{OI} 2$ inch; and that from 5 to 9 p.m. it rose 660 inch. The absolutely lowest pressure was $27^{\circ}$. $^{\circ}$ inches at 2.30 p.m., which is the lowest on record in Mauritus.

"From 9 a.m. on the 28 th to I p.m. on the 29 th the mean direction of the wind did not vary much, but it occasionally showed a tendency to veer towards north, being at times from north-east by north to north-northeast. Between I and 2 p.m. it on the whole veered to north, and between 2 and 3 p.m. to west-north-west, oscillating considerably, and soon after settling down at west-south-west.

"After I I a.m. the velocity of the wind increased much, being at I p.m. at the rate of 96.5 miles an hour, and at I.2O at the rate of 104 miles. But from I.25 to 2.30 p.m. there was a lull, the velocity decreasing to the rate of 43 miles an hour at 2.33 p.m. It then besan to increase again, and at 3.47 p.m. was at the rate of $\mathrm{I} 2 \mathrm{I} \cdot 2$ miles per hour, but it soon began to abate, being at the rate of 72 miles at 5.20 p.m., 60 miles at 6 p.m., 47 miles at 7 p.m. and 26 miles at 9 p.m. By this time the weather was fine, the sky partially clear, and here and there stars shining brightly.

"Seeing that from 9 a.m. on the 24 th to 9 a.m. on the 27 th the barometer had fallen from 30.059 to $29^{\circ} 903$ inches, and that the wind, though light, had veered from east-south-east half south to east by south, a note was sent to the newspapers on the latter day, stating that there was heavy weather to the northward, and that it had existed since the 24th ; which, as usual in such circumstances, meant that there were indications of a cyclone away to the northward and that it was travelling from north-eastward to south-westward.

"But the wind having by 9 a.m. on the 28 th reached north-east by east, and the barometer being higher on the 27 th at the same hour, there was no apprehension; and in the afternoon of the 28 th, the wind being still moderate from north-eastward, and the barometer falling at the rate of only 0.003 inch per hour, it was announced that there was no fear.

"As already stated, it was only on the 29th that the conditions became unfavourable, and at 9.40 a.m. a telegram was despatched announcing that the barometer was falling at an accelerating rate.

"Other telegrams, despatched at II a.m., announced that the velocity of the wind was at the rate of 52 miles an hour in the squalls, and that probably it would not exceed 56 miles an hour. Soon afterwards the telegraph wires were broken, and all communication ceased.

"The barometer continuing to fall at an accelerating rate, and the mean direction of the wind being nearly constant, it was inferred that the centre of the depression would, contrary to long experience (the wind being from north-east) pass over the island, and that the wind would then come from nearly the opposite direction.

"The centre, however did not pass over the Observatory, but over a point about six miles to the westward of it, and apparently from that point it travelled across the island on an east-south-easterly course.

"As a rule, when the wind is from north-eastward, there is scarcely any danger of a hurricane in Mauritius. All our great hurricanes have commenced, not with a north-easterly, but with a south-easterly wind; and this is why, when the wind was from north-east by east at II a.m. yesterday, and the barometer at $29.33^{8}$, it was No. I I 80 , VOL. 46 ] considered probable that the velocity of the wind would not exceed 56 miles an hour. On February 12 last, the barometer fell to 29.325 , and the greatest velocity of the wind was $47^{\circ} 5$ miles per hour from north-east, the barometer soon afterwards rising and the wind decreasing.

" There are, apparently, only two ways of, in a measure, accounting for the passage of the centre of a hurricane over the island yesterday from west-north-westward to east south-eastward. Firstly, the cyclone which had been travelling to the northward and north-westward of the island on a south-westerly course, from the 24 th to the 27 th, recurved to the southward and south-eastward; or secondly, a small secondary cyclone, which was generated in the south-east quadrant of the larger cyclone, travelled to the east-south-eastward, and bore down on Mauritius. The latter is perhaps the more probable hypothesis ; for the small but violent hurricane of yesterday, with respect to its extent, duration, \&c., exhibited the characteristics of a local atmospheric disturbance.

"On the night of the 27 th and morning of the 28 th there was a great deal of thunder and lightning, and also frequent lightning during the night of the $28 \mathrm{th}$. But the hurricanes of Mauritius are seldom, if ever, immediately preceded by thunder and lightning.

"It may be stated, also, that from the $25^{\text {th }}$ to the 29 th there were from five to six groups of sun-spots, indicating a considerable increase of solar activity; and that from the 25 th to the 28 th there were large magnetic disturbances, the portion of the sun's disk on which there was a very large group of spots on February i2 being again on or near the sun's central meridian.

"C. Meldrum."

\section{PROFESSOR JAMES THOMSON}

PROF. JAMES THOMSON, who died on May 8, after a few days' illness, the result of a chill, was born in Belfast in I822. He was the son of James Thomson, who was then Lecturer on, and afterwards Professor of, Mathematics in Belfast, and subsequently became Professor of Mathematics in Glasgow University. The father was a highly successful teacher and original investigator in mathematics, and was the author of many important school books. One of these books was, thirty years ago, still the recognized text-book on arithmetic in Ireland, and in all probability still retains its position. It was referred to by its very well-known title the "Thomson," by Prof. Tyndall in his British Association Address in I 874. We do not need the assurances of contemporaries, which are plentiful, that the two boys, James and William Thomson (now Lord Kelvin), made brilliant progress in their father's subject, and exhibited, even in early days, that combination of inventive genius and painstaking effort for accuracy, which have been their great characteristics since. James took his M.A. degree at Glasgow, served an apprenticeship under Sir William Fairbairn, and practised in Belfast as an engineer. $\mathrm{He}$ held the appointments of engineer to the Belfast Water Commissioners and to the Lagan Canal Navigation Works. In 1857 he became Professor of Civil Engineering in Queen's College, Belfast, and his Belfast pupils are to be found occupying high positions in every part of the world. He succeeded Rankine in Glasgow in 1872, and resigned the Professorship at Glasgow in I 889 because his eyesight was failing. He became a Fellow of the Royal Society in 1877 . He received the honorary degrees of D.Sc. from the Queen's University of Ireland, and of LL.D. from Glasgow and from Dublin. In 1853 he married the only daughter of the late $\mathrm{Mr}$. William John Hancock, J.P., of Lurgan, Co. Armagh, and it is a pathetic circumstance connected with his death, that she and one of his daughters survived him only a few days. He leaves a son and another daughter. 
In his private engineering practice at Belfast, he carried out important work in hydraulic machinery for use at home and in foreign countries. $\mathrm{He}$ invented the inward flow vortex turbine, and even now there are men in Ulster who are willing to talk at great length about his troubles and successes with this turbine. There was no practical man, however clever, who did not at first ridicule the scientific young gentleman who proposed to replace an eighty foot wheel by a tiny turbine, whose wheel was less than a foot in diameter. He never in his life could have had a happier moment than that in which, surrounded by crowds of astonished rustics and practical engineers, he saw this tiny wheel in its very first trial, driving the machinery of a large mill. And now, wherever turbines are to be found all over the world, they are mostly "Thomson" turbines, made on the principles so clearly thought out and described by him, albeit they are known under many very different names. His notions on such subjects as strength of materials and the effect of initial strains in materials, although published forty-four years ago, have only lately become the notions of practical engineers. At that early date, his ideas on many of the applications of science in engineering were very clear and correct, and far in advance of his contemporaries. He is especially to be recognized for his services in practical hydrodynamics, a subject in which there has been a more misleading appearance of mathematical theory than in any other branch of engineering. To one of Thomson's pupils it is positively painful to take up any authoritative treatise on hydraulic machinery, for he knows that nearly every page of troublesome mathematical reasoning is based on some absurd assumption, and that James Thomson's few propositions are almost the only ones on which the engineer can rely. James Thomson seemed to fear the misuse by young engineers of the recognized mathematical methods of attacking physical problems. He, himself, when he used mathematical expressions, used them merely to put before others the results of his own method of reasoning. It expresses only a part of the truth to say that he thought about things geometrically rather than algebraically. $\mathrm{He}$ refrained from publication until his proof was perfect, and some of his pupils may feel sorry that they have not more faithfully followed their master's example. A study of his successive manuscript proofs of his law of flow of fluids from similar orifices would probably enable us to conceive of the habits of thought of the Greek geometers : every word and phrase is carefully selected, and considered time after time with a view to perfect accuracy. Such invention and such regard for perfection of detail were surely never combined before.

When any of his speculations has been once published in an authoritative text-book, it will be noticed that it appears in all text-books published subsequently; the melting point of ice, the triple point in water-stuff, the continuity in the steam water isothermal, the tears of strong wine, are a few examples. No doubt, as time goes on, text-book writers will find that he discovered other important things. $\mathrm{He}$ was such a very observant man that he often put forward his most important propositions when explaining phenomena that seemed utterly insignificant. Let the reader only think that what occurs in a wash-basin, or in a little rivulet near the sea, may be of great importance scientifically, and let him read again some of Thomson's insignificant-looking scattered papers, and he will find important propositions published which will not, perhaps, for some years yet, find their proper positions in the text-books.

Of the history of thermodynamics during the eventful years $1849-50$, who dares now to say anything? Nor can anyone now say anything about the great glacier dispute. One thing is certain, however, that James Thomson's discovery of the necessary lowering of the melting-point of ice with pressure, published on January
2,1849 , settled for ever the theory of the flow of glaciers. Joule's work was beginning to be known, but Thomson, in his proof, like Lord Kelvin in the well-known paper published on the same day, adopts Carnot's idea of the conservation of heat. A change in one expression, not essential to the proof itself, was all that was needed after the first and second laws of thermodynamics had been recognized. Of his various papers on hydrodynamics, capillarity, heat, light, and the states of matter, published since that time, we have not space to say more than that each of them made a substantial addition to our knowledge. His latest work, the Bakerian Lecture this year of the Royal Society, on "The Grand Currents of Atmospheric Circulation," is such a paper as we might expect from a man who had given more than thirty-five years of study to the subject, that subject being one which was peculiarly his own. It is possible that the practical engineer, judging from the title merely, may neglect to read a paper which is one of phenomenal importance to the engineer as well as to the physiographer.

He was a man of singular purity of mind and simplicity of character, very clear-sighted in all that pertained to moral right and wrong, and conscientious to a degree. In his presence one felt in a purer atmosphere, where mean things seemed impossible. No Professor was ever so willing to take trouble (not mere momentary trouble, but trouble of days and nights) in the interests of a student, but no Professor was ever so rigidly exact in giving certificates and testimonials. The present writer has talked often with his old pupils about him, but never met one of them, who, besides a great respect, had not also a genuine and kindly and pleasurable love for his old Professor, whose kindness and patience had been unfailing, and whose sympathy had many a time been extended to him. How useless it is to speak of the good done to the world by a man of his character. Every one of his pupils, in however small or great a degree, is extending the range of his influence.

\section{JEAN SERVAIS STAS}

THE regret expressed in the obituary notice of Jean Servais Stas, that we had not the exact words of his famous discourse delivered before the King of the Belgians, has attracted the attention of a correspondent, who has very courteously sent us the text of the speech.

It was delivered by J. S. Stas in his capacity of President of the Royal Academy of Sciences, and was addressed to the King at the New Year's reception, January I, I89r. We have much pleasure in laying a translation of it before our readers :-

$$
\text { "Sire, }
$$

"The Royal Academy of Science, Literature, and the Fine Arts expresses its sincere wishes for the happiness of your Majesty, and the prosperity of your reign.

"As the central organ of the intellectual movement of the country, the Academy seeks to comprise within its arms the most varied talents, and to remain always an adequate and living expression of the entire activity of the human mind.

"This is both its duty and the reason for its existence. "In the sphere of Literature and Art its voice is almost always safely guided by public opinion-a competent judge of works accessible to all.

"It is otherwise in the sphere of Science.

"The physical, mathematical, and natural sciences, and even the moral and political sciences, do not appeal in the same degree to public opinion. If their conquests radiate afar, if they incessantly modify the conditions of social existence, they themselves develop in restricted circles, and work out of sight and of knowledge of the multitude. 